\section{Decrease in reducing power of aqueous humor originating from glaucomatous rabbits}

Introduction

Glaucoma, the second leading cause of blindness worldwide, ${ }^{1}$ is characterized by gradual loss of retinal ganglion cells (RGC), ${ }^{2}$ resulting in a distinct appearance of the optic disc loss of axons and a concomitant pattern of visual field loss. Additionally, increased mortality has been observed among glaucoma patients, making glaucoma a significant source of morbidity and mortality. ${ }^{3}$ Although it has traditionally been associated with high intraocular pressure (IOP), glaucoma is now considered a multifactorial disease. In this context, IOP is the leading known risk factor for the development of optic nerve neuropathy. ${ }^{4,5}$ Oxidative stress has been considered to contribute to the morphologic and physiologic alterations in aqueous humor (AH) outflow and subsequently to RGC damage in glaucoma. ${ }^{6}$ The oxidative damage attributed to reactive oxygen species (ROS) in biological systems includes lipid and protein peroxidation processes, DNA damage, enzyme inactivation, and induction of signal transduction pathways. Two classes of endogenous mechanisms neutralize ROS, antioxidant enzymes and low molecular weight antioxidants (LMWA). ${ }^{7}$ LMWA donate electron(s) to ROS and readily penetrate cells providing site-specific protection against oxidative stress. ${ }^{8}$

A variety of defensive mechanisms against free radicals formed by light-catalysed reactions protect trabecular meshwork (TM) cells.9,10 In vitro studies have demonstrated a decrease in aqueous outflow facility when glutathione was depleted, ${ }^{11}$ or after perfusion with hydrogen peroxide when pressure was elevated. ${ }^{12}$ Vascular ischemia in the optic nerve may lead to oxidative injury to RGC during reperfusion. ${ }^{13}$ In addition, nitric oxide, following reaction with superoxide anions, may damage retinal ganglion cells. ${ }^{14}$ Finally, various injurious
Received: 29 August 2005 Accepted in revised form: 7 March 2006 Published online: 21 April 2006
${ }^{1}$ Department of Clinical
Pharmacology, Ben-Gurio University of the Negev,

E Beit-Yan

Pharmacology,

Ben-Gurion University of the Negev, POB 653

Israel

Fax: + 97286477629
Keywords: glaucoma; aqueous humor; cyclic voltammetry; rabbit; antioxidants; intra ocular pressure
Eye (2007) 21, 658-664. doi:10.1038/sj.eye.6702353; published online 21 April 2006 probably a result of chronic oxidative stress caused by the pathology. The differences in the first anodic wave are mainly due to a fall


triggers, such as excess of glutamate, induces the programmed apoptotic death of RGC, which is mediated in part by free radical damage. ${ }^{15,16-18}$

\section{Glaucoma models}

In vivo glaucoma models are usually developed in laboratory animals by destroying the trabecular system thus creating obstruction of the AH outflow. This condition creates an acute elevation of the IOP, which is a glaucoma condition. There are several approaches to destroy the trabecular system: laser irradiation, ${ }^{19}$ $\alpha$-chymotrypsine administration, photocoagulation following India ink injection, ${ }^{20,21}$ and aqueous vein obstruction. $^{22}$ All these models have the common property of being an artificial model trying to mimic the human disease and have the same weak aspects: (a) creation of acute elevation of IOP, which has no identity to the disease in humans. Primary open angle glaucoma (POAG) in humans is a gradual slow rise of the IOP; (b) the creation of this model involves an inflammatory reaction that is not related to glaucoma, but does include oxidative stress and oxidative damage to proteins, lipoproteins, and DNA.

\section{Congenital glaucoma in New Zealand rabbits}

The sporadic appearance of CGR in a normal colony of New Zealand albino rabbits was reported in $1962 .{ }^{23}$ This is an autosomal recessive gene, which is responsible for the disgenesis of the outflow system in the eye. We succeeded in creating a colony of CGR by inbreeding sporadic cases of glaucoma rabbits from a normal colony. The third generation presented bilateral glaucoma symptoms at birth. Histology evaluation of the glaucomatous eyes revealed atrophy of the TM and the aqueous plexus (corresponding to the human canal of Schlemm), located posterior to the peripheral margin of the anterior chamber angle. ${ }^{24}$

\section{Cyclic voltammetry}

A cyclic voltammetry (CV) method has been developed for measuring and evaluating the overall reducing capacity derived from the LMWA (scavengers). The principle governing this method is based on a common chemical characteristic of the scavengers, the ability to donate electrons to ROS and, as a result, to scavenge them. It was hypothesized and then demonstrated that an evaluation of the overall reducing power of a biological sample correlates with the overall scavenging activity of the sample. In order to quantify the total reducing power, the $\mathrm{CV}$ method was applied. The resulting measurements correlated with the antioxidant activity of both hydrophilic and lipophilic scavengers. The method is suitable for use in biological fluids and in tissue homogenates, and can supply information concerning the type of antioxidants and their total concentration without having to determine specific compounds. ${ }^{25}$ The CV approach for total reducing capacity evaluation will be used to compare differences between CGR and control rabbits in different eye tissue reducing equivalent content.

\section{Materials and methods}

Sporadic cases of unilateral congenital glaucoma found in a normal colony of New Zealand rabbits were set for an inbreeding program. In the third generation, all individuals had bilateral glaucoma that was present at birth and could be detected from the time the neonates first opened their eyes at the age of 10 days. ${ }^{24}$ A group of six rabbits, 12-24 months-of-age, male and female were selected for the present study. A group of normal animals of identical ages served as controls. The experiment was performed in accordance with the ARVO Statement for the Use of Animals in Ophthalmic and Vision Research. The animal research review committee of Tel-Aviv University approved the project. The animals were held under a 12-h day-night cycle. They were fed and had access to water ad libitum.

\section{IOP measurement}

The Mentor ${ }^{\mathrm{TM}} 30$ tonograph was calibrated according to the manufacturer's instructions. The rabbits were maintained in a restriction cage for the shortest period as possible prior to IOP measurements being taken, in order to avoid stress that might affect the results. All the measurements were taken at $1200 \mathrm{~h}$, to minimize daily fluctuations. Measurements were carried out after applying two drops of Benoxinate $\mathrm{HCl} 0.4 \%$ (Localine ${ }^{\odot}$ ) eye drops to each eye. IOP was measured in each eye at least four times. In cases where large fluctuations in the specific measurement were noticed, additional measurements were taken in order to reduce the standard deviation.

\section{AH sampling}

Following anesthesia (Ketamine 35 and Xylazine $5 \mathrm{mg} /$ $\mathrm{kg}$ ), a $30 \mathrm{~g}$ needle attached to a syringe, was introduced in the anterior chamber of the rabbits. A volume of 200-250 $\mu \mathrm{l}$ of $\mathrm{AH}$ was drained from the left and the right eyes, and kept in an eppendorph tube at $-70^{\circ} \mathrm{C}$. $\mathrm{AH}$ samples were taken from the right eye at the same time from the glaucomatic rabbit and their mach control group. A week later, following the recovery of the right 
eyes, AH samples were taken from the left eyes of the glaucomatous and control rabbits. All the samples were taken at mid day in order to reduce the daily fluctuation effects.

\section{Cyclic voltammetry}

The total reducing power, which correlates with the overall LMWA activity, was measured using CV. The measurements were carried out with a CHI model 620B $\mathrm{CV}$ apparatus (CH Instruments Inc., Austin, TX, USA). $\mathrm{CV}$ tracings were recorded from -0.3 to $1.3 \mathrm{~V}$ at a rate of $100 \mathrm{mV} / \mathrm{s}$ vs an $\mathrm{Ag} / \mathrm{AgCl}$ reference electrode. A threeelectrode system was used throughout the study. The working electrode was a glassy carbon disc $(\mathrm{CH} 104, \mathrm{CH}$ Instruments Inc.), $3.0 \mathrm{~mm}$ in diameter. Platinum wire served as a counter electrode. The working electrode was polished before each measurement with a polishing kit (CHI120, CH Instruments Inc.). Analysis of CV tracings and determination of peak potential $E_{\max }$ and the detector anodic current $(\mu \mathrm{A})$ were carried out as previously described. ${ }^{25}$ At least three tracings were recorded for each sample, and the repeated scans were similar. A change of greater than $50 \mathrm{mV}$ in peak potential was considered significant and attributed to the presence of another LMWA equivalent or group with a different peak potential. ${ }^{26}$

\section{HPLC-EC}

In order to identify the individual hydrophilic compounds composing the cyclic voltammer waves, proteins were precipitated from the sample by the addition of $2 \%$ perchlorate. Samples were filtered $(0.22 \mu)$ and aliquots $(20 \mu)$ were injected into an HPLC apparatus (Kontron, Switzerland) equipped with an electrochemical detector (ED; Bioanalytical systems, West Lafayette, IN). The mobile phase was used to evaluate the water soluble LMWA (uric acid and ascorbic acid) was $0.1 \mathrm{M}$ acetate buffer, $\mathrm{pH}=4.75$, containing $1 \%$ tetra butyl ammonium hydroxide. ${ }^{27}$ The samples were diluted in the mobile phase $1: 1$. A reverse phase $\mathrm{C}-18$ (Merck) column was used. The electrochemical detector was set at potential according to the CV measurements. Standards of uric acid and ascorbic acid were prepared as described by Motchnik et al..$^{27}$

\section{Statistical analysis}

Results were analysed using the two-tailed Student's $t$-test. Data were expressed as mean $\pm \mathrm{SD}$ and $P$-values $<0.05$ were considered significant.

\section{Results}

The CGR presented abnormally large eye globes and corneas. This pathology was the result of continuous high IOP that created mechanical stretch on the eye globe walls and expanded the dimensions of the eye globe.

IOP and eye size: The CGR used in this experiment had significantly elevated IOP in the left and right eyes, causing a buphthalmic eye as expressed in the enlargement of the eye size. No significant differences between the left and right eyes were found. In Picture 1 the effect of elevated IOP causing buphthalmic eye is shown in a rabbit from the second generation suffering from unilateral congenital glaucoma. The congenital glaucomatic rabbit exhibited a significant elevation in IOP $(P<0.001)$ and a significant eye enlargement $(P<0.001)$ (Table 1).

\section{Cyclic voltammetry}

The voltammogram of rabbit AH driven from the left and the right eyes, revealed two anodic peaks, each represent an antioxidant or a group of LMWAs with a close
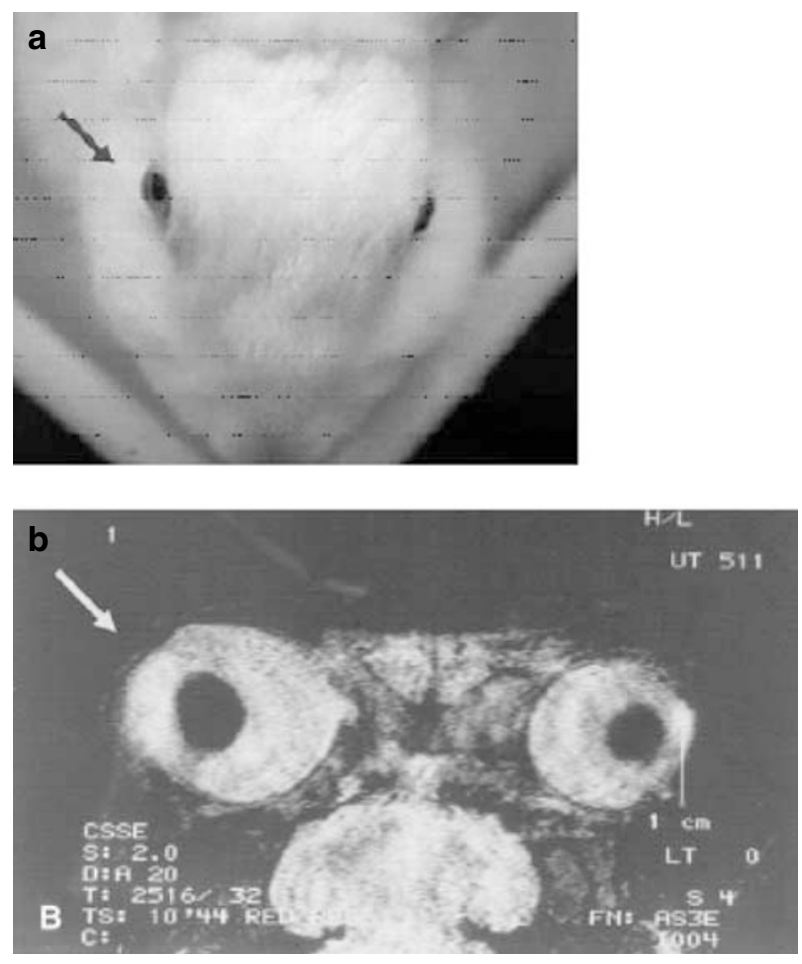

Picture 1 The effect of elevated intraocular pressure causing buphthalmic eye in a rabbit suffering from unilateral congenital glaucoma. (a) Unilateral glaucoma in a rabbit. The right eye is affected (arrow). (b) Magnetic resonance image of the same animal, showing the greatly differing dimensions of the glaucomatous eye and the normal eye. 
Table 1 Congenital glaucomatic rabbit eye size and intraocular pressure

\begin{tabular}{lcc}
\hline & $\begin{array}{c}\text { Congenital } \\
\text { glaucomatic rabbit }\end{array}$ & Control rabbits \\
\hline Eye size $(\mathrm{mm})$ & & \\
$\quad$ Right & $18.50 \pm 0.50$ & $13.73 \pm 0.25$ \\
Left & $18.00 \pm 0.00$ & $13.97 \pm 0.50$ \\
Mean L $+\mathrm{R}( \pm \mathrm{SD})$ & $18.25 \pm 0.20$ & $13.85 \pm 0.21$ \\
& & \\
Intraocular pressure $(m m H g)$ & & \\
$\quad$ Right & $33.13 \pm 3.82$ & $14.47 \pm 0.93$ \\
Left & $33.93 \pm 0.65$ & $13.73 \pm 2.50$ \\
Mean L $+\mathrm{R}( \pm \mathrm{SD})$ & $33.53 \pm 2.49$ & $14.10 \pm 1.74$ \\
\hline
\end{tabular}

$\mathrm{SD}$, standard deviation of the mean.



Figure 1 Voltammogram of rabbit AH. A typical voltammogram of rabbit $\mathrm{AH}$. The lower voltammogram $(\ominus)$ is from control rabbit $\mathrm{AH}$, and the upper voltammogram $(-\times-)$ is from a congenital glaucomatic rabbit. In both voltammograms, two anodic peaks were found, indicating two groups of low molecular weight antioxidants; the first (marked with an arrow), at $268 \mathrm{mV}$, and the second anodic peak (marked with dashed arrow), at $731 \mathrm{mV}$. The same composition of LMWA is found in the two-tested group. The $y$-axis at the voltammogram expresses the current that was measured at the anodic peak. This current is proportional to the amount of the LMWA antioxidant presented in the tested $\mathrm{AH}$, normalized to the protein content. We find that there is a significant reduction in the LMWA content of the AH of CGR at the first anodic peak $(P=0.02)$. There were no differences in the LMWA content of the AH of congenital glaucomatic rabbit $v$ s the control group.

reducing power. The first peak at $268.50 \pm 16.29 \mathrm{mV}$ (mean value of the tested rabbits) had the reducing power of ascorbic acid and the second one, at $731.41 \pm 43.58 \mathrm{mV}$ (mean value of the tested rabbits), is typical for tryptophan, carnosine, and melatonin (Figure 1). The appearance of the same anodic peak in the control group of rabbits and the CGR reflects no changes in the composition of the LMWA in the AH although the CGR are exposed to a continuously elevated IOP. The $y$-axis at the voltammogram expresses the current

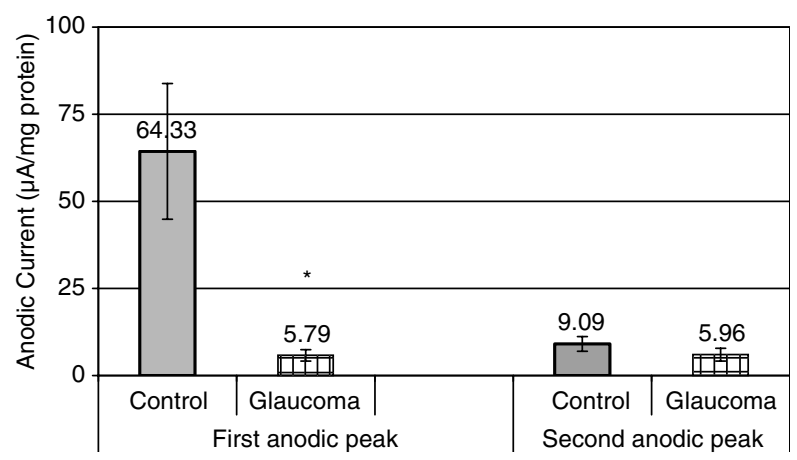

Figure 2 Low molecular weight antioxidant content of congenital glaucomatic rabbits vs controls. LMWA content of congenital glaucomatic rabbit $\mathrm{AH}$ is significantly reduced at the first anodic peak, $(P=0.02)$ vs the matched control group. There are no differences in the amount of LMWA with lower potency as shown at the second anodic peak.

measured at the anodic peak. This current is proportional to the amount of the LMWA antioxidant presented in the tested $\mathrm{AH}$, normalized to the protein content. We found that there is a significant reduction in the LMWA content of the AH of CGR at the first anodic peak $(P=0.02)$. There were no differences in the LMWA content of the AH of congenital glaucomatic rabbits $v$ s the control group (Figure 2).

\section{HPLC-EC}

The nature of the first anodic peak was further determined to specifically analyse the correspondent antioxidant that is involved in the significant activity in the congenital glaucomatous $\mathrm{AH}$ reduction. We tested the anodic peak composition by an HPLC equipped with an electrochemical detector set at the potential identical to the CV analysis and found the same paradigm, namely there is a significant reduction in the amount of the major component of the first anodic peak, ascorbic acid. Ascorbic acid concentration in the congenital glaucomatous rabbit $\mathrm{AH}$ was $10 \%$ of the control group values $(P<0.001$; Figure 3). A similar reduction of $69 \%$ was found for uric acid in the congenital glaucomatous rabbit.

\section{Discussion}

We can conclude that the changes in reducing capacity are limited to the more potent antioxidants.

Oxidative damage has been associated with several pathologic conditions of the eye, including glaucoma. Several ocular degenerative disorders have been studied, and evidence of oxidative stress was provided in terms of markers of lipid peroxidation, activity of antioxidant 
Ascorbic acid in Rabbit Aqueous humor

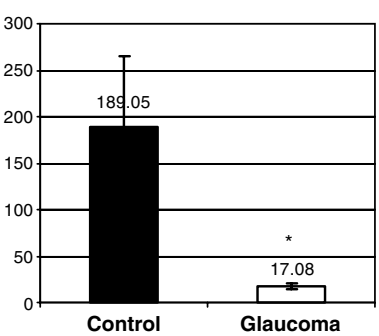

Uric acid in Rabbit Aqueous humor



Figure 3 Ascorbic acid and uric acid in rabbit AH. A significant reduction in the aqueous content of ascorbic acid and uric acid was found in the congenital glaucomatic rabbits, HPLC equipped with an electrochemical detector.

enzymes, and the levels of low molecular weight antioxidants. ${ }^{28}$ Few studies have been published on the role of antioxidant therapy or oxidative damage in experimental glaucoma. Ko et $a l^{29}$ demonstrated the synergistic effect of S-PBN, a potent radical scavenger, and BDNF application in an experimental model of glaucoma. Izzoti et $a l^{30}$ published another clue for the involvement of free radical-mediated damage in glaucoma. They showed an elevation in 8-OH-D Guanosine, an indicator of oxidative DNA damage, in the TM of glaucoma patients. The linkage between oxidative stress and retinal damage in a rat model of glaucoma was recently shown. ${ }^{31}$ A recent study evaluated oxidative markers in glaucoma patients' $\mathrm{AH} .{ }^{32}$ and concluded that oxidative stress may lead to an induction of antioxidant enzymes and contribute to total reactive antioxidant potential (TRAP) decrease.

When looking at the changes in the LMWA in the $\mathrm{AH}$, it is necessary to consider the nature of experimental glaucoma. Inflammatory processes accompanying some models may interfere with the LMWA balance at the sclera and/or the uvea and there for affect the $\mathrm{AH}$ LMWA content. When evaluating the antioxidant capacity of AH obtained from donors, you lack a real control group as you cannot get $\mathrm{AH}$ from healthy donors. In addition, the glaucomatic patients are under various medical treatments that probably affect the degree of oxidative stress. It is accepted that cataract patients will serve as a control group, although the oxidative stress these patient are exposed to is well-documented. In the present study, we tested the effect of elevated IOP on the LMWA content of the $\mathrm{AH}$ in a congenital glaucomatic rabbit model, free of any iatrogenity disturbing of the cellular LMWA. This unique model of chronic POAG expressed most of the clinical parameters found in human POAG. ${ }^{24}$ The chronic long-term elevated IOP created elevated levels of nitrous oxide in these rabbits and in the retina of glaucoma patients. ${ }^{33}$ An increase in the immunoreactivity of constitutive heat shock protein
HS70 in the retina, rather than of the inducible one, found in these congenital glaucomatic rabbits, suggests an adaptation response to chronic elevated IOP. ${ }^{34}$ In the present study, rabbits IOP is chronically elevated and beyond daily fluctuations it is kept significantly high. The permanent elevated IOP prevent a correlation analysis of the changes in the $\mathrm{AH}$ redox state along IOP. AH is known to contain several active oxidative agents such as hydrogen peroxide and superoxide anion. ${ }^{35}$ It has been suggested that chronic oxidative stress insult induced by this agent can compromise TM function. ${ }^{11,33,36}$ Antioxidant status of biologic samples is regarded as an indicator of oxidative stress. A decrease in the antioxidant capacity of tissues and body fluids may be the consequence of increased oxidative processes. Among the methods that determine the antioxidant capacity of a biologic sample, TRAP is one of the most commonly used procedures. ${ }^{37,38}$ For many years, voltammetry measurements have been conducted to evaluate electron transfer between molecules and evaluation of redox potential of redox active compounds. ${ }^{39} \mathrm{CV}$ was used to evaluate the overall reducing power of biological samples. ${ }^{25}$ These measurements are usually carried out for isolated compounds under specific conditions. With the CV techniques, an electrical potential gradient is applied (relative to a reference electrode) across an electrodesolution interface (working electrode) to oxidize or reduce species present in solution (in the case of $\mathrm{CV}$, a linear gradient is applied). The resulting current $v s$ potential is recorded (cyclic voltammogram). Since this method for total reducing capacity was introduced, ${ }^{40,41}$ it has been used in a variety of clinical and pathological conditions. ${ }^{25,26,41}$ Biological fluids and tissue homogenates were used in the CV method for LMWA estimation. This paper describes, for the first time, the use of $\mathrm{CV}$ to determine total reducing capacity of the $\mathrm{AH}$ analysis. These results indicate a significant reduction in the level of water-soluble antioxidants in the $\mathrm{AH}$ (including glutathione, ascorbate, and tyrosine). This decrease may be due to the occurrence of oxidative stress in the glaucomatous eye that makes the organ more susceptible to the damage associated with ROS production. Further study on newborn congenital glaucomatic rabbit will be able to explore the correlation between the development of the elevated IOP and the retinal ganglion cells loss along with changes in the $\mathrm{AH}$ redox state.

\section{References}

1 Quigley HA. Number of people with glaucoma worldwide. Br J Ophthalmol 1996; 80: 389-393. 
2 Hernandez MR, Pena JD. The optic nerve head in glaucomatous optic neuropathy. Arch Ophthalmol 1997; 115: 389-395.

3 Egge K, Zahl PH. Survival of glaucoma patients. Acta Ophthalmol Scand 1999; 77: 397-401.

4 Sommer A. Intraocular pressure and glaucoma. Am J Ophthalmol 1989; 107: 186-188.

5 Bengtsson B, Heijl A. A long-term prospective study of risk factors for glaucomatous visual field loss in patients with ocular hypertension. J Glaucoma 2005; 14: 135-138.

6 Green K. Free radicals and aging of anterior segment tissues of the eye: a hypothesis. Ophthalmic Res 1995; 27(Suppl 1): 143-149.

7 Ames BN, Shigenaga MK, Hagen TM. Oxidants, antioxidants, and the degenerative diseases of aging. Proc Natl Acad Sci USA 1993; 90: 7915-7922.

8 Kohen R, Nyska A. Oxidation of biological systems: oxidative stress phenomena, antioxidants, redox reactions, and methods for their quantification. Toxicol Pathol 2002; 30: 620-650.

9 Freedman SF, Anderson PJ, Epstein DL. Superoxide dismutase and catalase of calf trabecular meshwork. Invest Ophthalmol Vis Sci 1985; 26: 1330-1335.

10 Nguyen KP, Weiss H, Karageuzian LN, Anderson PJ, Epstein DL. Glutathione reductase of calf trabecular meshwork. Invest Ophthalmol Vis Sci 1985; 26: 887-890.

11 Kahn MG, Giblin FJ, Epstein DL. Glutathione in calf trabecular meshwork and its relation to aqueous humor outflow facility. Invest Ophthalmol Vis Sci 1983; 24: 1283-1287.

12 Yan DB, Trope GE, Ethier CR, Menon IA, Wakeham A. Effects of hydrogen peroxide-induced oxidative damage on outflow facility and washout in pig eyes. Invest Ophthalmol Vis Sci 1991; 32: 2515-2520.

13 Flammer J, Haefliger IO, Orgul S, Resink T. Vascular dysregulation: a principal risk factor for glaucomatous damage? J Glaucoma 1999; 8: 212-219.

14 Lipton SA, Lipson SA, Choi YB, Pan ZH, Lei SZ, Chen HS et al. A redox-based mechanism for the neuroprotective and neurodestructive effects of nitric oxide and related nitroso-compounds. Nature 1993; 364: 626-632.

15 Bautista RD. Glaucomatous neurodegeneration and the concept of neuroprotection. Int Ophthalmol Clin 1999; 39: 57-70.

16 Ratan RR, Baraban JM. Apoptotic death in an in vitro model of neuronal oxidative stress. Clin Exp Pharmacol Physiol 1995; 22: 309-310.

17 Choi YB, Lipton SA. Redox modulation of the NMDA receptor. Cell Mol Life Sci 2000; 57: 1535-1541.

18 Mittag T, Schmidt KG. Mechanisms of neuroprotection against glaucoma. Ophthalmologe 2004; 101: 1076-1086.

19 Percicot CL, Schnell CR, Debon C, Hariton C. Continuous intraocular pressure measurement by telemetry in alpha-chymotrypsin-induced glaucoma model in the rabbit: effects of timolol, dorzolamide, and epinephrine. J Pharmacol Toxicol Methods 1996; 36: 223-228.

20 Ueda J, Sawaguchi S, Hanyu T, Yaoeda K, Fukuchi T, Abe $\mathrm{H}$ et al. Experimental glaucoma model in the rat induced by laser trabecular photocoagulation after an intracameral injection of India ink. Jpn J Ophthalmol 1998; 42: 337-344.

21 Gu Z, Yamamoto T, Kaware C, Matsubara B, Kawase K, Sawada A et al. Neuroprotective effect of $N$-methyl-
D-aspartate receptor antagonists in an experimental glaucoma model in the rat. Nippon Ganka Gakkai Zasshi 2000; 104: $11-16$

22 Morrison JC, Moore CG, Deppmeier LM, Gold BG, Beshul CK, Johnson EC et al. A rat model of chronic pressure-induced optic nerve damage. Exp Eye Res 1997; 64: 85-96.

23 Luntz MH. Experimental glaucoma in rabbits. Trans Ophthalmol Soc UK 1962; 82: 271-282.

24 Ueno A, Tawara A, Kubota T, Ohnishi Y, Inomata H, Solomon AS et al. Histopathological changes in iridocorneal angle of inherited glaucoma in rabbits. Graefes Arch Clin Exp Ophthalmol 1999; 237: 654-660.

25 Kohen R, Beit-Yannai E, Berry EM, Tirosh O. Overall low molecular weight antioxidant activity of biological fluids and tissues by cyclic voltammetry. Methods Enzymol 1999; 300: 285-296.

26 Kohen R. The use of cyclic voltammetry for the evaluation of oxidative damage in biological samples. J Pharmacol Toxicol Methods 1993; 29: 185-193.

27 Motchnik PA, Frei B, Ames BN. Measurement of antioxidants in human blood plasma. Methods Enzymol 1994; 234: 269-279.

28 Takahashi A, Masuda A, Sun M, Centonze VE, Herman B. Oxidative stress-induced apoptosis is associated with alterations in mitochondrial caspase activity and Bcl-2dependent alterations in mitochondrial $\mathrm{pH}(\mathrm{pHm})$. Brain Res Bull 2004; 62: 497-504.

29 Ko ML, Hu DN, Ritch R, Sharma SC. The combined effect of brain-derived neurotrophic factor and a free radical scavenger in experimental glaucoma. Invest Ophthalmol Vis Sci 2000; 41: 2967-2971.

30 Izzotti A, Sacca SC, Cartiglia C, De Flora S. Oxidative deoxyribonucleic acid damage in the eyes of glaucoma patients. Am J Med 2003; 114: 638-646.

31 Ko ML, Peng PH, Ma MC, Ritch R, Chen CF. Dynamic changes in reactive oxygen species and antioxidant levels in retinas in experimental glaucoma. Free Radic Biol Med 2005; 39: 365-373.

32 Ferreira SM, Lerner SF, Brunzini R, Evelson PA, Llesuy SF. Oxidative stress markers in aqueous humor of glaucoma patients. Am J Ophthalmol 2004; 137: 62-69.

33 Geyer O, Wolman Y, Chemihovsky T, Iaina A, Lazar M, Solomon AS. Elevatated NO levels in buphthalmic glaucomatous rabbit eyes. IVOS 1996; 37: S834.

34 Tytell M, Geyer O, Kent CR, Dean DO, Solomon AS. Retinal heat shock protein immunoreactivity in glaucoma. IOVS 1999; 40: S265.

35 Spector A, Garner WH. Hydrogen peroxide and human cataract. Exp Eye Res 1981; 33: 673-681.

36 De La Paz MA, Epstein DL. Effect of age on superoxide dismutase activity of human trabecular meshwork. Invest Ophthalmol Vis Sci 1996; 37: 1849-1853.

37 Lissi E, Salim-Hanna M, Pascual C, del Castillo MD. Evaluation of total antioxidant potential (TRAP) and total antioxidant reactivity from luminol-enhanced chemiluminescence measurements. Free Radic Biol Med 1995; 18: 153-158.

38 Lissi E, Pascual C, del Castillo MD. On the use of the quenching of luminol luminescence to evaluate SOD activity. Free Radic Biol Med 1994; 16: 833-837.

39 Bard AJ, Faulkner LR. Electrochemical Methods: Found Elemental and Applications. John \& Wiley \& Sons Inc.: New York, 1980. 
40 Kohen R, Tirosh O, Gorodetsky R. The biological reductive capacity of tissues is decreased following exposure to oxidative stress: a cyclic voltammetry study of irradiated rats. Free Radic Res Commun 1992; 17: 239-248.
41 Shohami E, Gati I, Beit-Yannai E, Trembovler V, Kohen R. Closed head injury in the rat induces whole body oxidative stress: overall reducing antioxidant profile. J Neurotrauma 1999; 16: 365-376. 